by the colleges of advanced technology and with its implications for postgraduate study and research, education and industrial training generally, while Prof. Wiseman examined the part played by toacher training colleges as 'alternatives' to a university education. Both speakers insisted on the need to provide for some cross-over or transfer from college of technology or teacher training college to university and vice versa and on the importance of a broadly based education. Dr. P. F. R. (now Sir Percy) Venables referred to the necessity for all institutions of higher education to think in terms of university quality in determining their conditions, and in particular there should be adequate opportunities for higher study and research and professional contacts by way of travel, sabbatical leave and attendance at conferences. Prof. Wiseman's contention that the provision of teaching should be under the æeis of the universities was fully supported, but sandwich courses were not generally accepted as advantageous.

Sir Noel Hall thought that up to 1939 contacts between the university world and industry generally were much more limited in number and scope than those in other advanced countries and quite inadequate for the post-war demand, although in finance and public administration a pattern of relations had developed where practitioners welcomed discussion with university men and women on the problems of their own day-to-day responsibilities.
Much re-thinking was now taking place in industry, and probably among university appointments committees, on the placement of graduates in industry, leading to developments which were steadily improving contacts betwoen universities and industry in this respect. He thought that research by qualified univorsity people into the activities of industry itself was likely to continue to be difficult to organize and pursue, though he was not particularly concerned about the problem of secrecy. A greater difficulty was that of deciding the point in time at which important decisions had in fact been taken. This difficulty appeared to be diminishing and much activity was also being devoted to studying the tools of management.

Prof. Quarrell was concerned more with the conduct of research by universities on behalf of industry, discussing more particularly the research contract but emphasizing the value of formal opportunities for personal contacts between industrialists and members of a university through the university court, council and committess of council. In this discussion also the importance of a wider basic training for professional students was emphasized. However, the main stress was laid on the importance of personal contacts, including participation by industrialists in university government at the executive level. The desirability of avoiding the use of the term 'management' was recognized and of referring rather to 'business studies'.

\title{
THE BRITISH COAL UTILIZATION RESEARCH ASSOCIATION
}

T HE annual report for 1962 of the British Coal Utilization Research Association* includes a summary of the year's activities and lists of publications and lectures by the staff, information circulars, and membership of advisory committees and of research staff. The total staff of 310 at the end of the year comprised 63 in scientist grades, 115 in research officer and research assistant grades, 46 in clerical and administrative grades and 86 in industrial grades.

The bulk of the report is occupied by an account of research activities from which the following points are selected. A two-year programme on coal-fired boilers fitted with automatically controlled combustion equipment and ash-handling and coal-handling gear indicated that from the point of view of cost of steam generated as well as technically this assembly of coal-fired equipment can be recommended for industrial use in many localities and circumstances. Eight commercially produced solidfuel boilers with outputs from 33,000 to 60,000 B.Th.U./h have been tested using anthracite and coal under varying conditions to provide basic information for developing more efficient and automatic appliances with high amenity. * The Fritish Coal Utilization Research Association. Annual Report,
1962. Pp. 67. (Leatherhead: The British Coal Utilization Research Association. 1963.)
Work on deposits and corrosion in large water-tube boilers has already indicated that the composition and structure of deposits are independent of time, and has led to the devising of an infra-red spectrometric method for determining sulphur trioxide and to the investigation of laboratory methods for assessing quantitatively the effects of the nature of the ash and the composition of the flue gases on the corrosion of austenitic steels.

A systematic study of the slagging properties of British coals now nearing completion should assist in the choice of coals for slagging combustion, and basic studies of combustion and gasification have sought to provide busic information on the behaviour and decomposition of coals while being heated. The apparatus for studying pre-ignition and devolatilization of small particles of coal has been further developed, enabling the amount and rate of decomposition at known particle temperatures to be determined under effectively isothermal conditions. Among instrumental advances during the year were the further improvement of the venturi pneumatic pyrometer, the use of a nuclear magnetic resonance method, a microwave method for continuous measurement of moisture in coal, and the use of ciné-photography for studying the operation of the open-screw feeder and the quenching of slag discharged from a gasifier.

\section{TRIBOPHYSICS RESEARCH IN AUSTRALIA}

$\mathrm{T}$ HE Division of Tribophysics of the Commonwealth Scientific and Industrial Research Organization of Australia is a major centre of research on the physics and chemistry of surfaces of solids and on metal physics. The annual report for 1961-62 records that work continued on the friction and lubrication of surfaces*. Molybdenum disulphide has been shown to be superior in lubricating

* Commonwealth of Australia. Commonwealth Scientific and Industrial Research Organization. Annual Report of the Division of Tribophysics for the year ending June 30,1962 . Pp. $\mathrm{i}+19$. (Melbourne: Division of Tribophysics, C.S.I.R.O., 1962.) ability to many other inorganic compounds of comparable structure, and the effect of atmospheric humidity and water absorbed on the lubricant on burnishing and friction has been examined. Friction is highest at 100 per cent humidity. The theoretical study of how models of the atomic configurations of flat surfaces could, in principle, be constructed has now been applied to a number of different crystal structures and a set of photographs of models of about twenty of the simplest surfaces in each of the face-centred-cubic, body-centred-cubic, sodium chlor- 